\title{
Meconium Ileus
}

\section{Immediate and Long-term Survival}

\author{
J. F. MCPARTLIN, J. A. S. DICKSON, and V. A. J. SWAIN \\ From the Queen Elizabeth Hospital for Children, London
}

\begin{abstract}
McPartlin, J. F., Dickson, J. A. S., and Swain, V. A. J. (1972). Archives of Disease in Childhood, 47, 207. Meconium ileus: immediate and long-term survival. The results of surgery for meconium ileus obstruction (37 cases) at Queen Elizabeth Hospital for Children, London, during the years 1953 to 1970 are presented. The surgical survival was $30 \%$ in the years 1953 to 1961 , and $70 \%$ in the years 1962 to December 1970, inclusive. The long-term survival was $57 \%$. Complications, such as small bowel atresia, gangrene, and meconium peritonitis, were associated with a higher mortality. The adoption of the Bishop Koop operation in 1962 coincided with the increase in the survival rate. An association between meconium ileus and hypertrophic pyloric stenosis was noted.
\end{abstract}

Meconium ileus in the newborn is a wellrecognized complication of cystic fibrosis. Surgical treatment has in the past been disappointing. The first survivors were reported in 1948 (Hiatt and Wilson) but most series published in the past 10 years show a high mortality (Table I). A series from The Hospital for Sick Children, Great Ormond Street (Holsclaw, Eckstein, and Nixon,

Received 9 November 1971.
1965) reporting 109 cases from 1944 to 1964 , showed a surgical mortality of $58 \%$; only 20 of the 46 surgical survivors lived one year or longer.

This paper presents the results of treatment of meconium ileus at Queen Elizabeth Hospital for Children during the period 1953 to December 1970.

\section{Case Material}

During this period 37 cases of meconium ileus were seen. In all the diagnosis of cystic fibrosis was con-

TABLE I

Results of Surgical Treatment for Meconium Ileus

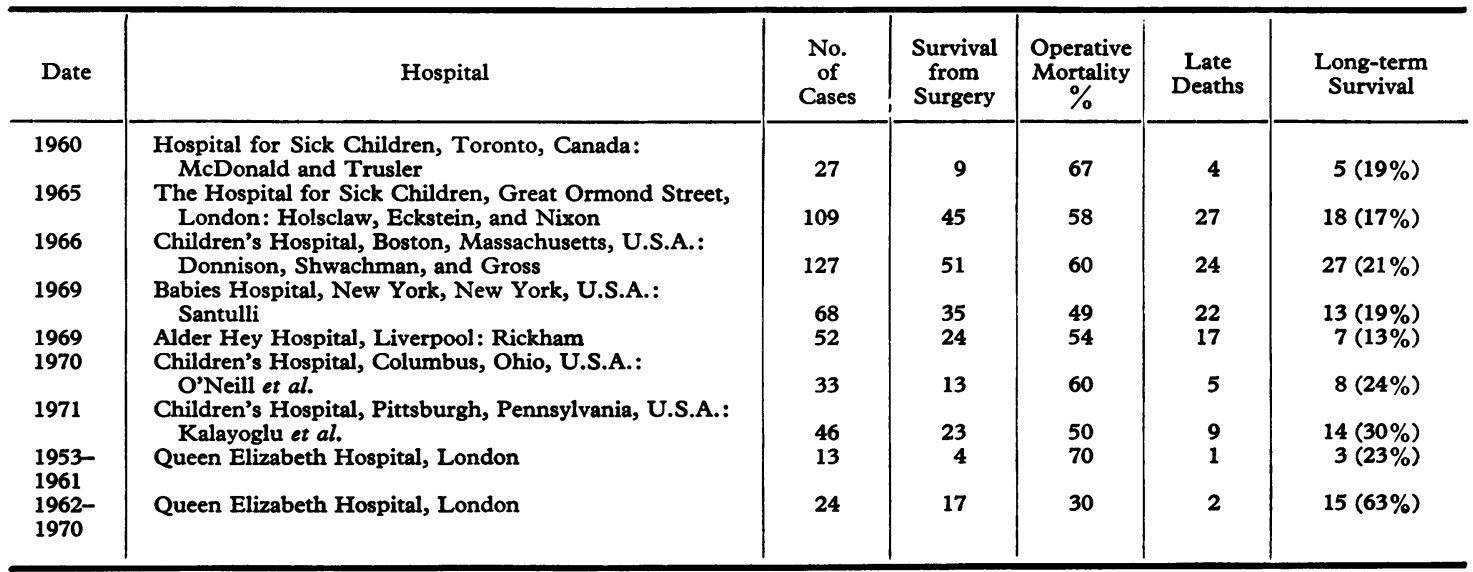


firmed by a sweat sodium of more than $70 \mathrm{mEq} / 1$. For purposes of comparison we have adopted the criteria of surgical survival used in the series from The Hospital for Sick Children, Great Ormond Street (Holsclaw et al., 1965): that is a survival of one month from the time of operation unless death occurred shortly after this due to further surgery.

During this period the total number of new cases of cystic fibrosis seen was 262 , and the incidence of meconium ileus was $13 \%$.

\section{Results}

Sex incidence. Boys and girls were approximately equally affected: 17 boys to 20 girls.

Birthweight. Fig. 1 shows the birthweights and deaths in the series. The weights fall within the normal range apart from the 2 who were under $2 \cdot 0 \mathrm{~kg}$, and both these babies died.

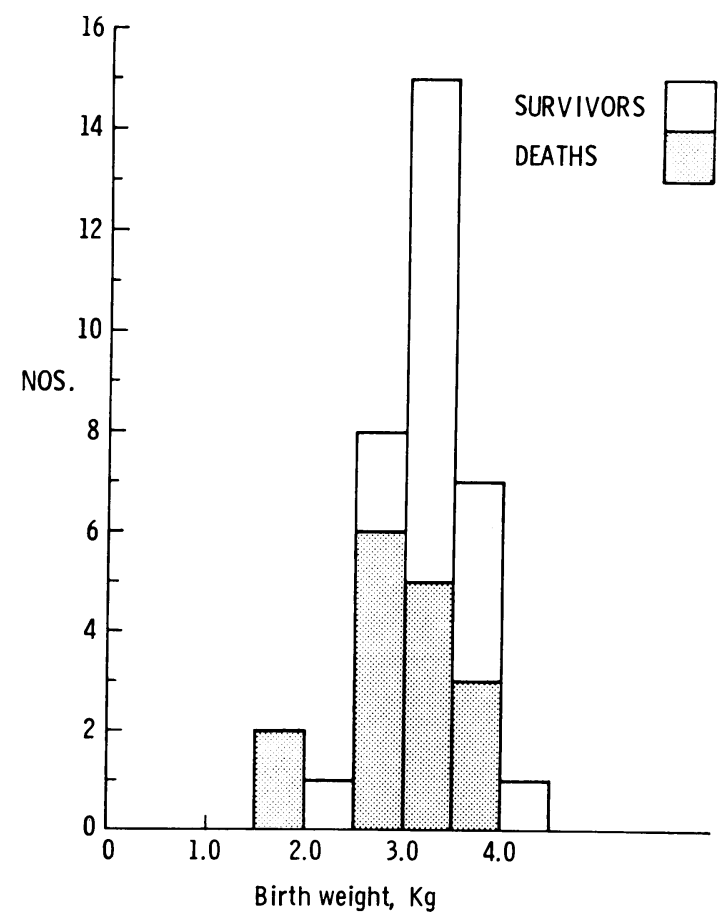

FIG. 1.-Histogram: birthweights and deaths in meconium ileus.

Associated conditions. There were 3 babies with hypertrophic pyloric stenosis among the 37 with meconium ileus. Since the average incidence of pyloric stenosis is about 3 per 1000 live births, the probability of this occurring randomly is small $(P<0.001)$. This association has not been recorded before.

In 2 cases the diagnosis of pyloric stenosis was $\overrightarrow{\overrightarrow{\vec{N}}}$ complicated by the problem of episodes of intestinal obstruction due to the other causes. One of these babies, who had had a second operation for adhesion obstruction on the 8th day of life, died 7 days after a Ramstedt's operation performed on the 34th day. The other 2 babies survived.

Factors influencing survival. The mortality $\overrightarrow{\vec{A}}$ rate of the operation before 1962 was $70 \%(9 / 13)$, whereas from 1962 to 1970 it was 30\% (7/24). Fig. 2 shows the relation of the timing of the first operation to survival. Those cases that had their operation on the first day of life had a higher is mortality $(11 / 16,69 \%)$ than those that were $N$ operated on later $(5 / 20,25 \%)$. The age at operation of one patient is unknown.

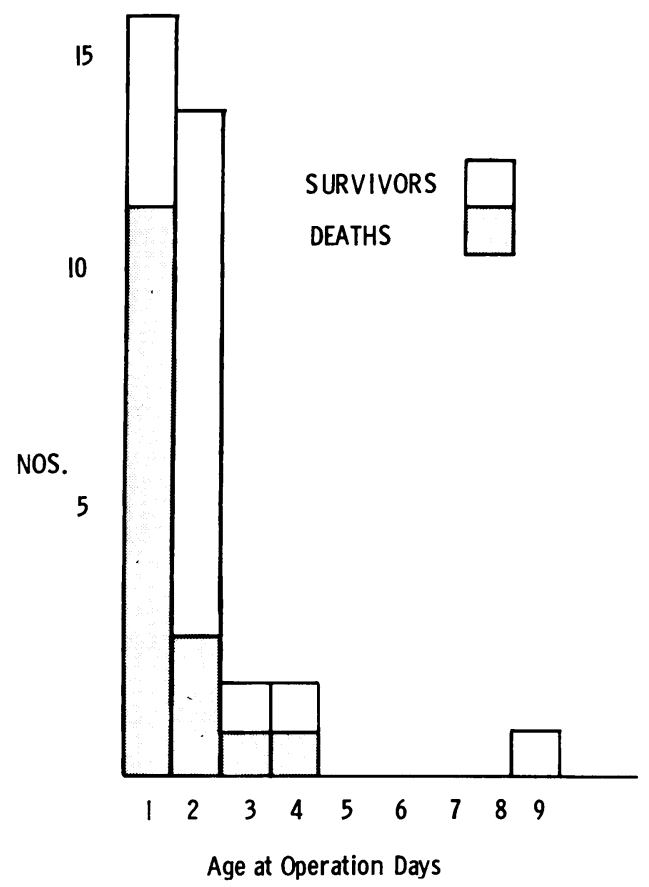

FIG. 2.-Histogram to show relation of age at operation to survival.

A higher mortality rate among babies operated upon on the first day of life is a common finding in neonatal surgery, and in general is a reflection of the fact that these babies are more acutely ill.

The incidence of complications and their effect on survival is shown in Table II. In those 
TABLE II

Complications at Original Operation

\begin{tabular}{|c|c|c|c|}
\hline & No. & Deaths & Survivors (\%) \\
\hline $\begin{array}{l}\text { Meconium ileus alone } \\
\text { Meconium ileus }+ \text { simple atresia volvulus or adhesions } \\
\text { Meconium ileus }+ \text { gangrene ( }+ \text { atresia or volvulus but no perforation) } \\
\text { Meconium ileus }+ \text { peritonitis }(+ \text { other complications) } \\
\text { Not known }\end{array}$ & $\begin{array}{r}16 \\
5 \\
5 \\
9 \\
2\end{array}$ & $\begin{array}{l}3 \\
2 \\
2 \\
9 \\
0\end{array}$ & $\begin{array}{r}81 \\
60 \\
60 \\
0\end{array}$ \\
\hline Total & 37 & 16 & \\
\hline
\end{tabular}

patients suffering from uncomplicated meconium obstruction the survival was $81 \%$, diminishing with the severity of complications to nil in cases of meconium peritonitis.

The death rate appears uninfluenced by sex-7 of 17 males died and 9 of 20 females.

\section{Discussion}

Table I gives the results of published series of surgically treated meconium ileus.

In 1962 the Bishop Koop (1957) operation became the procedure most commonly used at this hospital. In this operation after resection of the most dilated portion of the ileum an end-to-side proximal-to-distal ileo-ileal roux-en-Y anastomosis is performed, and the free end of the distal ileum brought out in the abdominal wall as an ileostomy (Fig. 3). The stoma acts as a safety valve and can be used to instil fluids, drugs, or detergents. On

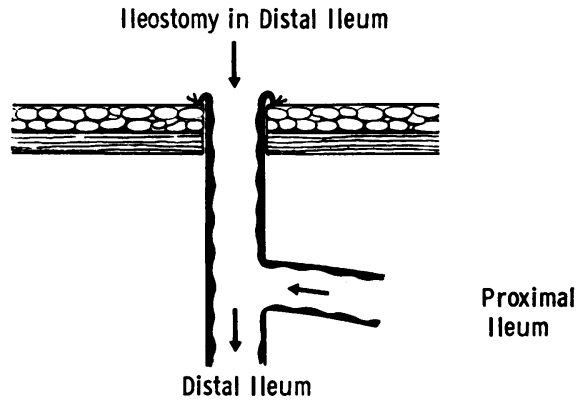

FIG. 3.-Diagram of the Bishop Koop anastomosis.

3 occasions we have relieved postoperative 'faecal plugging' obstructions by instilling 'Gastrografin' (Schering) into this stoma (McPartlin, Dickson, and Swain, 1972).

From the time of adoption of the Bishop Koop technique surgical survival improved from $30 \%$ to $70 \%$. This, combined with the fact that the survival rate in those cases where the operation was used was $74 \%$, compared with $31 \%$ when other techniques were used, suggests that it was an important factor.

However, if operation on the first day of life is taken as an index of severity of the disease, the series before and after 1962 are not strictly comparable. Before 1962, 7 of the 13 cases (54\%), and after 1962, 9 of the 23 cases (39\%), were operated on in the first 24 hours.

The long-term survival rate in this series has also been encouraging. Among the 21 surgical survivors there have been only 3 late deaths, which occurred between the ages 3 and 5 months, during a followup period of up to 17 years, a late mortality rate of $14 \%$.

These good long-term survival figures accord with the opinion expressed by Dr. Winifred Young, 'that children with meconium ileus probably had a better prognosis than children with fibrocystic disease diagnosed with respiratory infection, because the diagnosis was made shortly after birth, before irreversible lung damage had occurred ... our meconium ileus cases as a subgroup have a better prognosis than average' (Mearns, 1969). Recent results from The Hospital for Sick Children, Great Ormond Street (George and Norman, 1971), show a similar improved survival rate of $48 \%$ at 5 years, whereas up to 1965 only $6 \%$ survived to 1 year (Holsclaw et al., 1965).

We thank Dr. M. B. Mearns for her assistance in the care of these children, in the preparation of the paper, and the Medical Illustration Department of the Institute of Child Health, London, for the figures.

\section{REFERENCES}

Bishop, H. C., and Koop, C. E. (1957). Management of meconium ileus: resection, Roux-en-Y anastomosis and ileostomy irrigation with pancreatic enzymes. Annals of Surgery, 145, 410.

Donnison, A. B., Shwachman, H., and Gross, R. E. (1966). Review of 164 children with meconium ileus seen at the Children's Hospital Medical Center, Boston. Pediatrics, 37, 833.

George, L., and Norman, A. P. (1971). Life tables for cystic fibrosis. Archives of Disease in Childhood, 46, 139.

Hiatt, R. B., and Wilson, P. E. (1948). Celiac syndrome. VII. Therapy of meconium ileus. Surgery, Gynecology and Obstetrics, 87, 317 . 
Holsclaw, D. S., Eckstein, H. B., and Nixon, H. H. (1965). Meconium ileus: a 20-year review of 109 cases. American fournal of Diseases of Children, 109, 101.

Kalayoglu, M., Sieber, W. K., Rodnan, J. B., and Kiesewetter, W. B. (1971). Meconium ileus: a critical review of treatment and eventual prognosis. Fournal of Pediatric Surgery, 6, 290.

McDonald, J. A., and Trusler, G. A. (1960). Meconium ileus: an eleven-year review at the Hospital For Sick Children, Toronto, Canada. Canadian Medical Association fournal, 83, 881.

McPartlin, J. F., Dickson, J. A. S., and Swain, V. A. J. (1972) Meconium ileus: the use of gastrografin in the management of late faecal plugging. (In the press.)

Mearns, M. (1969). Discussion on the therapeutic and prophylactic use of mist tents. Proceedings of the 5th International Cystic Fibrosis Conference, p. 153. Ed. by D. Lawson. Cystic Fibrosis Trust, London.
O'Neill, J. A., Jr., Grosfeld, J. L., Boles, E. T., Jr., and Clatworthy, H. W., Jr. (1970). Surgical treatment of meconium ileus. American Fournal of Surgery, 119, 99.

Rickham, P. P. (1969). Intestinal obstruction due to abnormal meconium. In Neonatal Surgery, p. 366. Ed. by P. P. Rickham and J. H. Johnston. Butterworths, London.

Santulli, T. V. (1969). Meconium ileus. In Pediatric Surgery, 2nd ed., Vol. II, p. 851. Ed. by W. T. Mustard, M. M. Ravitch, W. H. Snyder, Jr., K. J. Welch, and C. D. Benson. Year Book Medical Publishers, Chicago.

Correspondence to Mr. J. A. S. Dickson, F.R.C.S., Institute of Child Health, 30 Guilford Street, London W.C.1. 